\title{
Variação na estrutura foliar de Mikania glomerata Spreng. (Asteraceae) sob diferentes condições de luminosidade ${ }^{1}$
}

\author{
ARI ESPINDOLA JUNIOR², MARIA REGINA TORRES BOEGER ${ }^{2,4}$, \\ AGENOR MACCARI JÚNIOR ${ }^{3}$, CARLOS BRUNO REISSMANN ${ }^{3}$ e FERNANDA LESSA RICKLI ${ }^{3}$
}

(recebido: 19 de abril de 2007; aceito: 09 de setembro de 2009)

\begin{abstract}
Variation on leaf structure of Mikania glomerata Spreng. (Asteraceae) under different light conditions). Variations in the leaf structure of Mikania glomerata Spreng. were investigated in distinct light regimes (high light, half-shade; shade; 100\%, 26,4\% and $13,8 \%$ of light intensity, respectively) associated to different vegetation types in the Araucaria Forest, Municipality of Castro, PR (2550'64” S and 4943'69” W). This study was designed to orient medicinal-plant producers to choose the best light condition for planting and to evaluate the potential use of medicinal species as an alternative to restore and to manage the understorey. After two years of the experiment, thirty seven leaves were collected from each treatment and the following parameters were analyzed: fresh and dry leaf mass, water content, leaf area, specific leaf area, stomata and trichome densities, lamina and petiole thickness and chlorophyll concentration. The higher mean values of fresh and dry mass, water content, leaf area and specific leaf area occurred in the leaves of the shade treatment, while the stomata and trichome densities, and lamina thickness presented higher values in leaves of the open-field treatment. The principal component analysis showed similarities between the leaves of the half-shade and high light treatments, suggesting that low light conditions are sufficient to stimulate leaf morphology responses. The higher mean values of leaf area and dry mass suggest a higher productivity on shade treatment. However, studies concerning growth rates, seasonal responses, and distinct nutrient conditions are necessary to complement information about more efficient cultivation methods.
\end{abstract}

Key words - guaco, leaf plasticity, light intensity, medicinal plants

RESUMO - (Variação na estrutura foliar de Mikania glomerata Spreng. (Asteraceae) sob diferentes condições de luminosidade). As variações estruturais foliares de Mikania glomerata Spreng. foram investigadas em distintas condições de luminosidade (pleno sol, meia-sombra e sombra; 100\%, 26,4\% e 13,8\% de intensidade luminosa, respectivamente) associadas a diferentes tipos de coberturas vegetais numa região de Floresta com Araucária, Município de Castro, PR (2550’64” S e 4943’69” W). Este estudo buscou subsidiar os produtores de plantas medicinais na escolha da melhor condição de luz para plantio, gerando informações sobre o potencial das plantas medicinais na recomposição e manejo do sub-bosque da área. Após dois anos de crescimento nos tratamentos, 37 folhas foram coletadas em cada tratamento, para a análise de massa foliar fresca e seca, teor de água, área foliar, área foliar específica, densidade de estômatos e de tricomas, espessura da lâmina e pecíolo e concentração de clorofila. Os maiores valores médios de massa foliar fresca, teor de água, área foliar e área foliar específica ocorreram nas folhas do tratamento sombra, enquanto a densidade estomática e de tricomas e a espessura da lâmina apresentaram maiores valores nas folhas do tratamento pleno sol. A análise dos componentes principais mostrou uma similaridade entre as folhas do tratamento meia-sombra e pleno sol, sugerindo que baixas intensidades luminosas são suficientes para estimular as respostas expressas pela morfologia foliar. Os maiores valores médios de área e massa fresca foliar sugerem uma maior produtividade no tratamento sombra, mas estudos referentes às taxas de crescimento da planta, respostas sazonais e condições nutricionais diferenciadas são necessários para complementar as informações para adoção de métodos de cultivo mais eficientes.

Palavras-chave - guaco, intensidade luminosa, plantas medicinais, plasticidade foliar

\section{Introdução}

Mikania glomerata Spreng., conhecida popularmente como guaco, é uma espécie herbácea de hábito volúvel,

1. Parte da dissertação de mestrado do primeiro autor, Programa de Pós-Graduação em Botânica, Universidade Federal do Paraná, Curitiba.

2. Universidade Federal do Paraná, Setor de Ciências Biológicas, Departamento de Botânica, Caixa Postal 19031, 81531-990 Curitiba, PR, Brasil.

3. Universidade Federal do Paraná, Setor de Ciências Agrárias, Departamento de Solos e Engenharia Agrícola, Rua dos Funcionários 1540, 80035-090 Curitiba, PR, Brasil.

4. Autor para correspondência: rboeger@ufpr.br com uso medicinal amplamente difundido na Região Sul do Brasil, ocorrendo em beira e interior de mata (Ritter \& Waechter 2004). Apresenta ramos lenhosos, cilíndricos, com folhas pecioladas, cordiformes-deltóides, agudas no ápice e curto-cordiformes na base (Pio-Correa 1984), encerrando propriedades medicinais, cujo extrato hidroalcoólico das folhas apresenta atividade antiinflamatória, efeito inibitório da musculatura intestinal e uterina e atividade broncodilatadora devido a cumarinas (Celeghini et al. 2001). O guaco vem sendo cultivado em sistemas de consórcios com outras espécies mais tradicionais, como a erva mate (Ilex paraguariensis A. St. Hil. - Aquifoliaceae), devido ao seu rápido 
crescimento e alto valor agregado (Lessa-Rickli et al. 2003), constituindo uma opção para obtenção de renda alternativa dos pequenos produtores.

Informações sobre as variações da morfologia foliar das espécies medicinais consorciadas em diferentes condições de luminosidade podem contribuir para o delineamento de métodos de cultivo de acordo com a exigência de luz de cada espécie. Deste modo, as características morfológicas representam, do ponto de vista produtivo, um fator importante tanto na safra que se pretende obter quanto na qualidade da droga vegetal fabricada a partir da matéria prima cultivada.

A luz, um dos principais fatores do ambiente físico, age de forma isolada ou conjunta no controle do desenvolvimento das plantas, interferindo no crescimento por meio do processo fotossintético e na diferenciação durante a morfogênese (Castro et al. 2003). As características morfológicas foliares respondem às diferentes intensidades luminosas ajustando a área de exposição, espessura e massa seca (Morais et al. 2004, Givnish et al. 2004, Montanari et al. 2004). Apesar da resposta das plantas frente à condição de luz não ser uniforme (Givnish 1988), estudos sobre a ação da variação da luz na estrutura foliar podem fornecer informações importantes, auxiliando na escolha dos regimes de plantio mais adequados para otimizar a produção em cultivo, como evidenciado nas investigações sobre Piper hispidinervium C. DC. (Santiago et al. 2001), Bouchea fluminensis (Vell.) Moldenke (Milaneze-Gutierre et al. 2003) e Coffea arabica L. (Morais et al. 2004).

O objetivo deste trabalho foi avaliar as variações estruturais das folhas de Mikania glomerata em três condições de luminosidade distintas (pleno sol, meiasombra e sombra), associadas, respectivamente, aos ambientes de campo, vegetação pouco densa e de bosque, utilizando as características morfológicas como indicadores de produção de massa verde foliar. Os dados obtidos neste estudo poderão ainda contribuir na avaliação da viabilidade de utilização da espécie estudada em reflorestamento de áreas improdutivas de fazendas, fomentando ações de recuperação e recomposição do sub-bosque nativo ou iniciativas de manejo.

\section{Material e métodos}

O experimento foi realizado na Fazenda Capão Bonito (2550'64” S e 4943’69” W), Município de Castro, Estado do Paraná (Brasil). O local apresenta diferentes tipos de fitofisionomias, ocorrendo áreas de campo, mata nativa, capoeira e reflorestamento por Pinus sp. A área de estudo localiza-se no Primeiro Planalto e apresenta temperatura média anual de $16,3^{\circ} \mathrm{C}$, sendo o mês mais quente $20,1^{\circ} \mathrm{C}$, e o mês mais frio $11,7^{\circ} \mathrm{C}$. O mês mais chuvoso é janeiro (200,1 mm) e o mês menos chuvoso é julho (80 mm), com precipitação anual de $1.469,1 \mathrm{~mm}$. A umidade relativa do ar varia entre $72,6 \%$ a $80,6 \%$. A região é climaticamente caracterizada como $\mathrm{Cfb}$ com clima quente-temperado, sempre úmido de acordo com a classificação de Koeppen (Maack 2002). O solo é do tipo Cambissolo Háplico Distrófico com alta relação silte-argila (Embrapa 1999), podendo ser considerado em processo de formação e liberação de nutrientes a partir da intemperização do silte. O pH é muito baixo, assim como os níveis de cálcio, magnésio, fósforo e potássio, enquanto as taxas de alumínio são altas. A concentração de nitrogênio, estimada a partir da quantificação de matéria orgânica no solo, foi considerada satisfatória para as condições de cultivo.

MudasdeMikaniaglomerata comtrintadias, emconsórcio com mudas de Bauhinia forficata Link. (Caesalpiniaceae), Maytenus ilicifolia Mart. ex Reiss. (Celastraceae), Vitex megapotamica (Spreng.) Moldenke (Verbenaceae) e Ilex paraguariensis A. St. Hil. (Aquifoliaceae), provenientes da indústria Chámel ${ }^{\circledR}$ foram plantadas em covas abertas com dimensões de 0,30 × 0,30 ×0,30 m, seguindo espaçamento de 1,5 metros entre as plantas e mantidas em condições naturais. Os locais de plantio foram selecionados e demarcados com estacas de madeira, delimitando três tratamentos distintos: área de campo (sol pleno) onde predomina vegetação herbácea, com $100 \%$ de intensidade luminosa; área de vegetação nativa pouco densa (tratamento meia-sombra) onde predomina floresta nativa pouco densa com $26,4 \%$ de intensidade luminosa e área de bosque (sombra) onde a floresta nativa está mais densa, com 13,8\% de intensidade luminosa. Cada tratamento foi composto por três parcelas e com nove mudas de cada espécie, por tratamento. A intensidade luminosa foi medida em cada um dos tratamentos, com luxímetro digital, para aferir o real sombreamento sobre as plantas. As medidas a campo foram feitas em três horários: 9h00, 12 h00 e 15h00, em três dias consecutivos, em intervalos de três meses a cada série de medições. Através destas medições foi possível quantificar a luminosidade incidente em cada tratamento: sol pleno (100\%), meia-sombra (26,4\%) e sombra $(13,8 \%)$.

Após dois anos de experimento, folhas de M. glomerata foram coletadas em todas as parcelas (amostragem mista), totalizando trinta e sete folhas totalmente expandidas em cada uma das condições de luz (pleno sol, meia-sombra e sombra), selecionadas dos $3^{\circ}$ e $4^{\circ}$ nós, no sentido ápice-base.

Destas, dezenove folhas por tratamento foram acondicionadas em sacos plásticos para mensuração da massa fresca através de balança analítica de precisão. Posteriormente, estas folhas foram prensadas entre papel jornal e secas em estufa a $50{ }^{\circ} \mathrm{C}$, até atingirem massa constante para a mensuração de suas respectivas massas secas. $O$ teor de água da folha foi calculado pela diferença entre massa fresca e seca foliar, expressa em percentagem (\%). Nestas folhas, a área foliar foi estimada utilizando-se a imagem digitalizada em "scanner" de mesa acoplado a computador, com auxílio do 
programa SIGMASCAN-PRO, Versão 5.0. A partir dos dados de área e massa seca foliar foi estimada a área específica foliar $(\mathrm{AEF})$ = área foliar/massa seca, segundo Witkowski \& Lamont (1991).

Doze segmentos da região mediana da lâmina foliar, entre o bordo e a nervura central, e seis segmentos da porção mediana do pecíolo, por tratamento, foram fixadas em FAA em etanol 70\% (Johansen 1940) e conservados em álcool etílico $70 \%$ para a mensuração do diâmetro do pecíolo e espessura dos tecidos. As mensurações das espessuras da lâmina e dos tecidos foram realizadas em microscópio óptico provido de ocular com escala micrometrada.

A densidade estomática e dos tricomas foi estimada utilizando-se a modelagem com esmalte incolor no terço mediano foliar. Os moldes epidérmicos foram montados entre lâmina e lamínula e a densidade foi estimada numa área previamente conhecida, situados em 19 campos, por tratamento.

Para a análise anatômica, as amostras da lâmina foliar e do pecíolo foram desidratadas em série etílica, incluídas em hidroxi-etil-metacrilato (Leica), seccionadas a $5 \mu \mathrm{m}$ de espessura e coradas com fucsina básica e azul de astra (Alves de Brito \& Alquini 1996) e montadas em resina sintética. As fotomicrografias foram obtidas em máquina digital Canon Power Shot F50 acoplada em microscópio Olympus BX51.

Para Microscopia Eletrônica de Varredura (MEV), o material fixado foi desidratado em série etílica, submetido a ponto crítico de $\mathrm{CO}_{2}$ e metalizado em ouro. As elétronmicrografias foram obtidas em microscópio eletrônico de varredura Jeol JSM-6360 LV. A micro-análise por dispersão de raios-X (EDS) foi realizada para quantificar concentração de silício na folha, em amostras analisadas em microscópio eletrônico de varredura, à baixo vácuo.

Discos de $1 \mathrm{~cm}^{2}$ de área da região intervenal de seis folhas por tratamento foram embalados no local de coleta em papel alumínio, acondicionados em caixa de isopor com gelo e em seguida transportados para o laboratório para a quantificação dos pigmentos foliares (clorofila a, clorofila b e clorofila total). A extração foi efetuada com $5 \mathrm{~mL}$ de acetona aquosa $80 \%$, com centrifugação do extrato em $1.500 \mathrm{rpm}$ e leitura de absorbância em espectrofotômetro Hitachi modelo U-2001, nos comprimentos de onda 647 nm e 664 nm. Para obtenção dos valores de concentração de clorofila aplicou-se nos resultados o coeficiente de extinção determinado por Porra et al. (1989).

Para todas as variáveis quantitativas foram calculadas as médias e os respectivos desvios-padrão. A análise de variância (ANOVA) foi utilizada para comparar as médias das características morfológicas, com nível de 5\% de probabilidade e a homogeneidade das variâncias foi testada pelo teste de Bartlett, com auxílio do programa Statistica versão 6.0. Dados com variâncias não homogêneas foram transformados em $\log (\mathrm{x}+1)$. As características morfológicas foram correlacionadas entre si em função dos tratamentos $(P<0,05)$ por meio do programa Statistica versão 6.0 e o grau de correlação $\left(\mathrm{r}^{2}\right)$ foi obtido de acordo com o proposto pelo Statistics Primer. A análise dos componentes principais (PCA) foi utilizada para determinar a maior variância entre as variáveis quantitativas, através do programa Past, versão 1,34 (Hammer et al. 2001).

\section{Resultados}

A análise de variância (ANOVA) mostrou que os valores médios de massa foliar fresca, teor de água, área foliar, área foliar específica (tabela 1), densidade de estômatos e de tricomas da face abaxial da lâmina foliar e a espessura do colênquima da face abaxial do pecíolo (tabela 2) diferiram significantemente entre os três tratamentos e foram maiores no tratamento sombra, com exceção da densidade de estômatos e de tricomas da face abaxial, cujos valores médios foram maiores no tratamento pleno sol.

Para a massa foliar seca (tabela 1) e espessuras total da lâmina, do mesofilo e do parênquima esponjoso (tabela 2) houve diferenças significativas apenas entre os tratamentos pleno sol e sombra. Os valores médios da espessura do parênquima paliçádico foram significativamente menores no tratamento sombra enquanto os valores médios de comprimento de pecíolo, número de camadas do colênquima do pecíolo e espessura do colênquima adaxial do pecíolo foram significativamente maiores nesse mesmo tratamento. $\mathrm{O}$ diâmetro médio do pecíolo foi diferente apenas entre os tratamentos pleno sol e sombra. As razões teor de água/ área foliar, parênquima paliçádico/esponjoso e clorofila a/b também não foram estatisticamente diferentes entre os tratamentos (tabelas 1 e 2). A área foliar apresentou uma correlação muito alta e positiva com as seguintes características: massa fresca $\left(\mathrm{r}^{2}=0,98, P<0,05\right)$, massa seca $\left(\mathrm{r}^{2}=0,89 ; P<0,05\right)$ e teor de água $\left(\mathrm{r}^{2}=0,95\right.$; $P<0,05)$ e uma relação moderada e negativa com as densidades de estômatos $\left(r^{2}=-0,45, P<0,05\right)$ e de tricomas da face abaxial $\left(\mathrm{r}^{2}=-0,68, P<0,05\right)$.

As folhas de $M$. glomerata caracterizam-se por apresentarem lâmina dorsiventral e serem pecioladas e horizontais em relação ao solo. Anatomicamente, a lâmina foliar é revestida por células epidérmicas, em vista frontal, com paredes anticlinais sinuosas e espessas em ambas as faces. Os estômatos são do tipo anomocítico e ocorrem apenas na face abaxial, caracterizando a folha como hipoestomática. Tricomas glandulares sésseis (figura 1) estão inseridos em depressão na camada epidérmica de ambas as faces. As células da cabeça distribuem-se em planos diferentes numa disposição em espiral (figura 2). A microanálise por dispersão de raios-X das folhas indicou uma alta concentração de 
Tabela 1. Valores médios e respectivos desvios padrão (entre parênteses) das características morfológicas e concentração de clorofila para folhas de Mikania glomerata em diferentes intensidades de luz.

Table 1. Mean values and standard deviation (in parenthesis) of the morphological characteristics and chlorophyll concentration for leaves of Mikania glomerata in different light intensities.

\begin{tabular}{|c|c|c|c|}
\hline \multirow{2}{*}{ Características morfológicas } & \multicolumn{3}{|c|}{ Tratamentos } \\
\hline & Pleno sol & Meia-sombra & Sombra \\
\hline Massa fresca foliar (g) & $1,8( \pm 0,5) c$ & $2,2( \pm 0,4) b$ & $4,1 \quad( \pm 1,2)$ a \\
\hline Massa seca foliar (g) & $0,27( \pm 0,07) b$ & $0,29( \pm 0,08) a b$ & $0,47( \pm 0,13) a$ \\
\hline Teor de água (g) & $1,56( \pm 0,47) c$ & $1,93( \pm 0,36) b$ & $3,65( \pm 1,08) a$ \\
\hline Área foliar $\left(\mathrm{cm}^{2}\right)$ & $39,4 \quad( \pm 11,3) \mathrm{c}$ & $50,0 \quad( \pm 9,8) b$ & $91,3 \quad( \pm 21,4)$ a \\
\hline $\operatorname{AEF}\left(\mathrm{cm}^{2} \mathrm{~g}^{-1}\right)$ & $145,6 \quad( \pm 16,3) \mathrm{c}$ & $174,6 \quad( \pm 34,1) b$ & $196,0 \quad( \pm 23,4)$ a \\
\hline Razão teor de água/área foliar & $39,6( \pm 3,6)$ a & $38,7 \quad( \pm 2,5)$ a & $39,4( \pm 3,1)$ a \\
\hline Concentração de clorofila a (nmol cm²-2) & $55,6( \pm 7,1)$ а & $45,4 \quad( \pm 10,3)$ a & $44,1 \quad( \pm 13,5)$ a \\
\hline Concentração de clorofila b $\left(\mathrm{nmol} \mathrm{cm}^{-2}\right)$ & $27,9 \quad( \pm 6,2) a$ & $23,3 \quad( \pm 4,9)$ a & $27,2( \pm 6,3)$ a \\
\hline Concentração de clorofila total (nmol cm²) & $86,5 \quad( \pm 9,6)$ a & $68,8 \quad( \pm 14,0)$ a & $71,4 \quad( \pm 18,1)$ a \\
\hline Razão clorofila a/b & $2,07( \pm 0,51)$ a & $1,97( \pm 0,33)$ a & $1,63( \pm 0,44) \mathrm{a}$ \\
\hline
\end{tabular}

Letras diferentes para mesma variável representam diferenças estatisticamente significativas entre os tratamentos testados (Tukey, $P<0,05)$. Different letters for same variable represent statistically distinct differences among treatments (Tukey, $P<0.05$ ).

Tabela 2. Valores médios e respectivos desvios padrão (entre parênteses) das características anatômicas das lâminas foliares e dos pecíolos de Mikania glomerata submetida a diferentes intensidades luminosas.

Table 2. Mean values and standard deviation (in parenthesis) of the anatomical characteristics of the leaf blades and petioles of Mikania glomerata submitted to different light intensities.

\begin{tabular}{|c|c|c|c|}
\hline \multirow{2}{*}{ Característica } & \multicolumn{3}{|c|}{ Tratamento } \\
\hline & Pleno sol & Meia-sombra & Sombra \\
\hline Espessura total da lâmina $(\mu \mathrm{m})$ & $393,1 \quad( \pm 54,0)$ a & $367,1 \quad( \pm 26,9) a b$ & $351,4 \quad( \pm 18,9) b$ \\
\hline Espessura do mesofilo $(\mu \mathrm{m})$ & $345,9 \quad( \pm 48,4)$ a & $311,4 \quad( \pm 23,0) a b$ & $299,9 \quad( \pm 20,1) b$ \\
\hline Espessura do parênquima paliçádico ( $\mu$ m) & $115,2 \quad( \pm 6,6)$ a & $109,5( \pm 7,5) a$ & $101,7 \quad( \pm 6,1) b$ \\
\hline Espessura do parênquima esponjoso ( $\mu \mathrm{m})$ & $228,3 \quad( \pm 34,6)$ a & $206,5 \quad( \pm 32,0) a b$ & $197,9 \quad( \pm 17,1) b$ \\
\hline Razão parênquima paliçádico/esponjoso & $0,51( \pm 0,07)$ a & $0,54( \pm 0,08) a$ & $0,52( \pm 0,06)$ a \\
\hline Espessura da epiderme da face abaxial ( $\mu \mathrm{m})$ & $22,6 \quad( \pm 1,2)$ a & $24,0 \quad( \pm 1,9)$ a & $22,8( \pm 1,2)$ a \\
\hline Espessura da epiderme da face adaxial ( $\mu \mathrm{m})$ & $25,4( \pm 1,9)$ a & $25,4( \pm 1,9)$ а & $25,4( \pm 1,6)$ a \\
\hline Densidade de estômatos $\left(\mathrm{n}^{\mathrm{o}} \mathrm{mm}^{-2}\right)$ & $147,2( \pm 16,0)$ a & $141,0 \quad( \pm 11,1) b$ & $123,8 \quad( \pm 7,8) c$ \\
\hline Densidade de tricomas da face abaxial $\left(n^{0} \mathrm{~mm}^{-2}\right)$ & $4,95( \pm 0,38) a$ & $3,83( \pm 0,87) b$ & $2,98( \pm 0,5) c$ \\
\hline Densidade de tricomas da face adaxial $\left(\mathrm{n}^{\mathrm{o}} \mathrm{mm}^{-2}\right)$ & $1,92( \pm 0,34)$ a & $1,38( \pm 0,28) b$ & $1,44( \pm 0,35) b$ \\
\hline Diâmetro do pecíolo (mm) & $2,45( \pm 0,14) b$ & $2,30( \pm 0,56)$ ab & $2,76( \pm 0,24)$ a \\
\hline Comprimento do pecíolo (cm) & $2,76( \pm 0,57) b$ & $2,83( \pm 0,49) b$ & $3,82( \pm 0,44)$ a \\
\hline № de camadas do colênquima do pecíolo & $5,2 \quad( \pm 0,4) b$ & $5,5 \quad( \pm 0,5) b$ & $6,5( \pm 0,5) a$ \\
\hline Espessura do colênquima abaxial do pecíolo $(\mu \mathrm{m})$ & $201,0 \quad( \pm 13) c$ & $255,0 \quad( \pm 20) b$ & $351,0 \quad( \pm 54)$ a \\
\hline Espessura do colênquima adaxial do pecíolo $(\mu \mathrm{m})$ & $175,0 \quad( \pm 14) b$ & $205,0 \quad( \pm 23) b$ & $232,0 \quad( \pm 14)$ a \\
\hline
\end{tabular}

Letras diferentes para mesma variável representam diferenças estatisticamente significativas entre os tratamentos testados (Tukey, $P<0,05)$. Different letters for same variable represent statistically distinct differences among treatments (Tukey, $P<0.05$ ). 

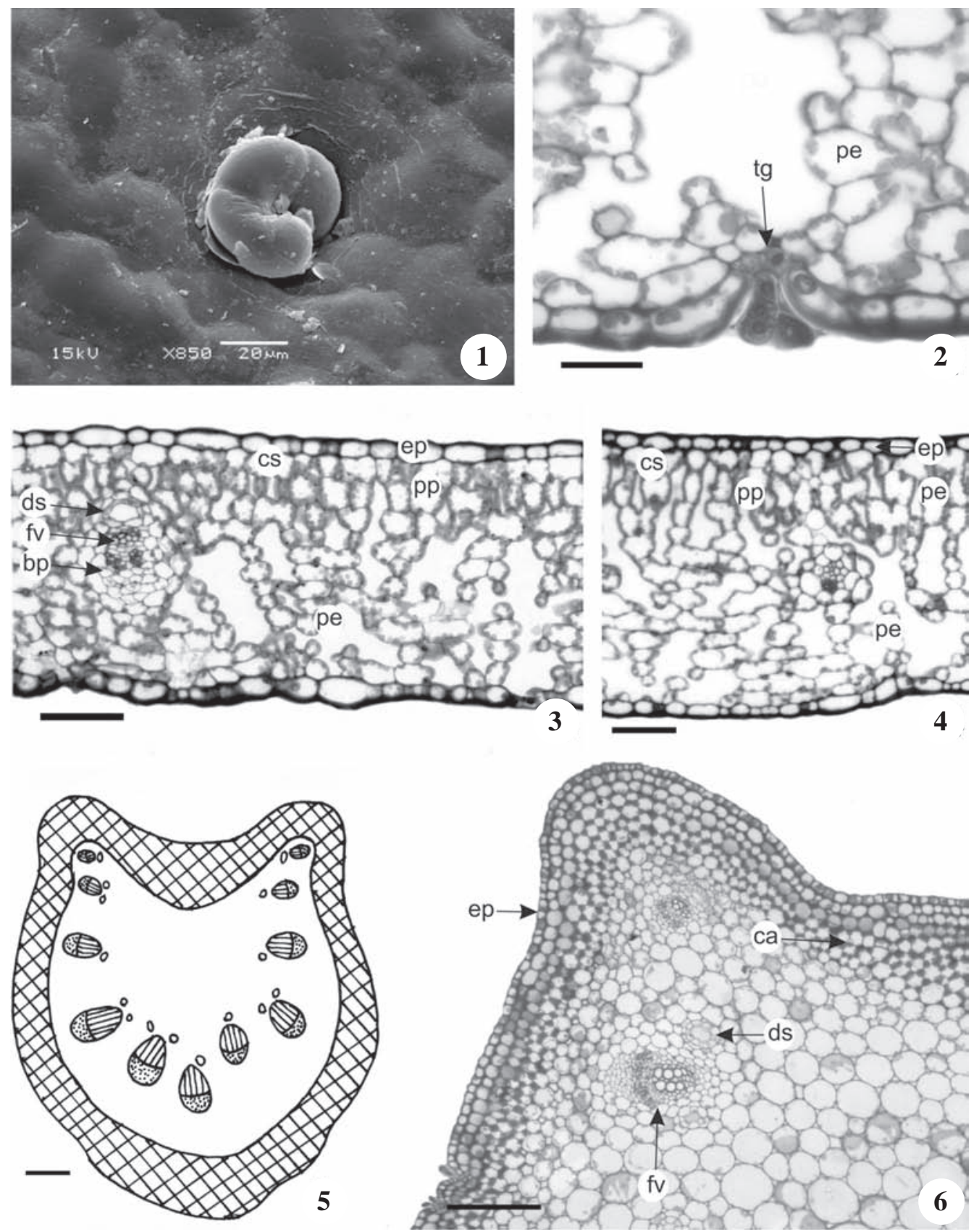

Figuras 1-6. Anatomia foliar de Mikania glomerata. 1. Tricoma glandular, na face adaxial da lâmina, em MEV. 2. Seção transversal da lâmina do tratamento meia-sombra, destacando tricoma glandular e parênquima esponjoso. 3. Seção transversal da lâmina do tratamento meia-sombra. 4. Seção transversal da lâmina do tratamento pleno sol. 5. Desenho esquemático do pecíolo

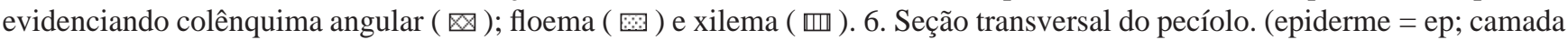
subepidérmica = cs; parênquima paliçádico = pp; parênquima esponjoso = pe; colênquima angular = ca; bainha parenquimática = bp; feixe vascular = fv; tricoma glandular = tg; ducto secretor = ds). Barra = $20 \mu \mathrm{m}(2), 100 \mu \mathrm{m}(3$ e 4), $200 \mu \mathrm{m}(5$ e 6).

Figures 1-6. Leaf anatomy of Mikania glomerata. 1. Glandular trichome from adaxial surface, in SEM. 2. Transverse section of the blade from half-shade treatment, showing glandular trichome and the spongy parenchyma. 3. Transverse section of the blade from half-shade treatment. 4. Transverse section of the blade from high light treatment. 5. Schematic drawing of the

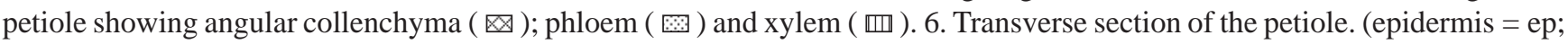
subepidermical layer = cs; palisade parenchyma $=$ pp; spongy parenchyma $=$ pe; angular collenchyma $=$ ca; parenchymatic bundle sheet $=\mathrm{bp}$; vascular bundle $=\mathrm{fv}$; glandular trichome $=$ tg; secretory duct $=\mathrm{ds})$. Bar $=20 \mu \mathrm{m}(2), 100 \mu \mathrm{m}(3$ and 4), $200 \mu \mathrm{m}$ (5 and 6). 
silício na região dos tricomas glandulares, em todos os tratamentos.

Em seção transversal, a epiderme é uniestratificada, com células que variam de retangulares a cúbicas, com paredes periclinais retas e cutícula delgada. Contígua à epiderme da face adaxial, ocorre uma camada subepidérmica aclorofilada (figura 3). Não foram observadas variações na organização da epiderme entre os tratamentos.

O mesofilo de $M$. glomerata é composto por uma ou duas camadas de parênquima paliçádico, discretamente diferenciado (figuras 3 e 4), caracterizado por células curtas, por vezes de forma irregular e arranjadas frouxamente. Nos tratamentos pleno sol e meia-sombra, as células paliçádicas são mais longas do que no tratamento sombra, porém o número de camadas celulares deste tecido não variou entre os tratamentos. O parênquima esponjoso é bem evidente, com cerca de 10 camadas, cujas células variam em tamanho e formato. Não foram observadas variações no número de camadas deste parênquima entre os tratamentos (figuras 3 e 4).

O pecíolo de $M$. glomerata, na região mediana, tende a forma oval com duas projeções na face adaxial (figuras 5 e 6), quando observado em seção transversal, apresentando uma camada de células epidérmicas pequenas e de formato cúbico. Tricomas glandulares podem estar presentes. Internamente à epiderme, cinco a oito camadas de colênquima angular formam uma bainha contínua. Os feixes vasculares colaterais, em número de sete a onze, estão dispostos em forma de arco, enquanto os ductos secretores estão dispostos internamente aos feixes vasculares (figuras 5 e 6 ).

A análise dos componentes principais (PCA) evidenciou, com base nas características morfológicas apresentadas, a distinção entre os tratamentos pleno sol e meia-sombra em relação ao tratamento sombra (figura 7). Esta análise mostrou que as folhas do tratamento sombra formam um grupo mais isolado quando comparado com as folhas dos tratamentos pleno sol e meia-sombra, para o conjunto de características analisadas. O PCA indicou ainda que PC1, representado principalmente pela área foliar, teor de água e comprimento do pecíolo, explicou 62,5\% da variância total (tabela 3), enquanto PC2, representado apenas pela espessura total da lâmina, explicou 13,1\% da variância. Juntos, PC1 e PC2 explicaram 75,6\% da variância dos dados estudados. PC1 indicou uma distribuição ampla das características morfológicas foliares, enquanto PC2 exibiu uma distribuição mais estreita para o mesmo conjunto de caracteres.

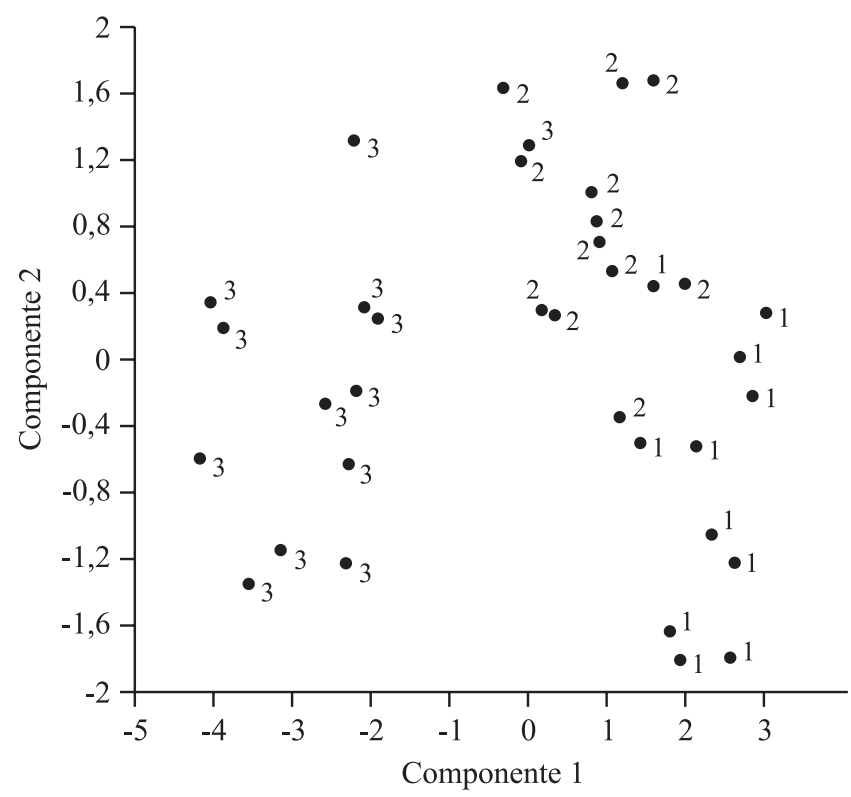

Figura 7. Análise dos componentes principais (PCA) para as características morfológicas de Mikania glomerata, dos tratamentos pleno sol (1), meia-sombra (2) e sombra (3).

Figure 7. Principal component analysis (PCA) for morphological characteristics of Mikania glomerata of high light (1), half shade (2), and shade (3) treatments.

Tabela 3. Componentes principais 1 (PC1) e 2 (PC2) obtidos a partir da matriz de correlação para as características morfoanatômicas das folhas de Mikania glomerata submetidas a diferentes intensidades luminosas.

Table 3. Principal components 1 (PC1) and 2 (PC2) obtained from the matrix of correlation for morpho-anatomical characteristics of leaves of Mikania glomerata submitted to different light intensities.

\begin{tabular}{lcc}
\hline Características morfológicas & PC 1 & PC 2 \\
\hline Massa foliar seca & $-0,853$ & 0,321 \\
Área foliar & $-0,951$ & 0,165 \\
Teor de água foliar & $-0,923$ & 0,109 \\
Comprimento do pecíolo & $-0,880$ & 0,129 \\
Espessura total da lâmina & 0,474 & 0,839 \\
Densidade estomática & 0,764 & 0,018 \\
Densidade de tricomas da face abaxial & 0,878 & 0,186 \\
Densidade de tricomas da face adaxial & 0,489 & 0,200 \\
Variância explicada pelos componentes & 5,08 & 0,98 \\
Percentagem do total da variância & $62,5 \%$ & $13,1 \%$ \\
explicada & &
\end{tabular}




\section{Discussão}

As folhas de M. glomerata responderam às diferentes intensidades luminosas como era esperado, apesar das respostas morfológicas não serem uniformes para todas as características analisadas. Características como massa seca, área foliar e espessura são consideradas as principais indicadoras de taxa de crescimento dos vegetais e os ajustes dessas características podem ser considerados estratégias desenvolvidas para maximizar a eficiência do uso dos diferentes recursos pelas plantas como, por exemplo, luz e nutrientes (Wilson et al. 1999, Vendramini et al. 2002). Os maiores valores de massa seca e área foliar no tratamento sombra refletiram também nos maiores valores de AEF. No entanto, os valores de AEF também são influenciados pela espessura e/ou a compactação dos tecidos da lâmina foliar (Wilson et al. 1999). Entre os tratamentos, a variação foi maior tanto para a massa seca (42,5\%) quanto para a área foliar (56,8\%), enquanto a espessura variou apenas $10,6 \%$, o que indica que a AEF parece ser mais dependente da massa seca e área foliar do que da espessura da lâmina. Dados semelhantes foram obtidos para a mesma espécie quando tratada sob diferentes fotoperíodos (Castro et al. 2003).

As variações da área foliar e da espessura da lâmina ao longo de um gradiente de luz representam a manutenção do volume foliar (Smith et al. 1997, Evans 1999, Ackerly et al. 2000), procurando maximizar a capacidade fotossintética da folha (Poorter 1999). A área foliar, que é maior em ambientes mais sombreados, indica o investimento da planta na maior superfície exposta para a interceptação dos raios luminosos, enquanto menores áreas foliares representam menor superfície exposta ao sol, o que torna a planta como um todo menos sujeita à transpiração e elevação da temperatura, sem comprometer a fotossíntese, uma vez que a luz é um recurso abundante (Niinemets \& Fleck 2002). A área foliar também parece ter especial influência na determinação do teor de água nas folhas, indicada pela razão entre o teor de água e área foliar entre os tratamentos, que se manteve praticamente constante, uma vez que os valores médios de espessura são inversamente relacionados com o teor de água.

Os maiores valores para espessura da lâmina em condições de luz mais intensa parecem ser resultado do aumento na espessura dos tecidos fotossintetizantes da lâmina foliar (Roças et al. 1997, Marques et al. 1999) e pelo alongamento das células do parênquima paliçádico (Roças et al. 1997, Castro et al. 1998, Cao 2000), uma vez que o número de camadas celulares praticamente se manteve o mesmo entre os tratamentos.
Apesar do incremento da espessura do parênquima paliçádico nas plantas dos tratamentos pleno sol e meiasombra em relação às plantas do tratamento sombra, a razão parênquima paliçádico/esponjoso se manteve $<1$ nos três tratamentos, indicando que também houve incremento na espessura do parênquima esponjoso na mesma proporção. A razão parênquima paliçádico/ esponjoso $<1$ é vantajosa em ambientes com menor intensidade luminosa, como um mecanismo de otimização de captura de luz (Vogelmann et al. 1996, Taiz \& Zeiger 2004). Em ambientes com maior luz disponível espera-se encontrar uma relação inversa, o que não foi observado neste estudo. Entre os três tratamentos, as folhas apresentaram a mesma razão parênquima paliçádico/esponjoso, apesar da diferença significativa entre as espessuras destes tecidos, principalmente entre os tratamentos pleno sol e sombra.

Maiores espessuras do parênquima esponjoso em relação ao parênquima paliçádico favorecem a luz difusa predominante nos tratamentos sombra e meia-sombra. As células do parênquima esponjoso, com formato irregular, associadas à maior fração de espaços intercelulares no interior da folha, geram maiores quantidades de luz difusa, aumentando a absorção da luz pelos cloroplastos dentro do mesofilo, tornando mais eficiente a distribuição da luz no interior da folha (Vogelmann et al. 1996).

Os resultados para as concentrações de clorofila não foram os esperados, uma vez que vários estudos sugerem que folhas de sombra usualmente possuem maior concentração de clorofila por unidade de massa seca e maior relação de clorofila b/a do que as folhas de sol. Tais características são interpretadas como uma adaptação para incrementar a absorção da luz vermelha que é limitada em ambientes sombreados (Cao 2000, Yano \& Terashima 2001) e a manutenção do balanço energético entre PSII e PSI (Cao 2000). Em contrapartida, alguns autores sugerem que não existem diferenças na razão clorofila a/b de plantas que se desenvolvem em diferentes graus de sombreamento (Gonçalves et al. 2001), como encontrado neste estudo. No entanto, é importante considerar que os valores médios de clorofila aqui obtidos foram por unidade de área, sendo dependentes da variação da espessura foliar. Provavelmente, concentrações de clorofila por unidade de massa podem apresentar resultados contrastantes, como evidenciado por Cao (2000) e Gonçalves et al. (2001).

Os maiores valores de densidade estomática e de tricomas no tratamento pleno sol também são influenciados pelo aumento da incidência luminosa (Roças et al. 1997, Castro et al. 1998, Klich 2000) e representam um maior controle sobre a transpiração, possibilitando reduzir a 
perda de água com abertura e fechamento dos estômatos, em condições mais favoráveis (Roças et al. 1997, Klich 2000). A presença de estômatos apenas na face abaxial é uma característica comum entre eudicotiledôneas (Fahn 1990) e um mecanismo fotoprotetor especialmente em ambientes de alta intensidade luminosa (Dickison 2000). A presença de tricomas tectores ou glandulares na superfície foliar pode ter inúmeras funções como proteger a folha da radiação excessiva em ambientes mais luminosos, auxiliar na manutenção da temperatura foliar, evitar a perda de água ou oferecer resistência a patógenos. Em ambientes mais sombreados, pode auxiliar na reflexão da radiação solar para o interior das células do mesofilo (Press 1999, Silva et al. 2005). Adicionalmente, a alta concentração de silício na região dos tricomas glandulares observada nas folhas de todos os tratamentos pode ser uma resposta a resistência a patógenos ou herbivoria (Silva et al. 2005).

Considerando que uma das principais funções do pecíolo é a sustentação e orientação da folha (Niinemets \& Fleck 2002), sua organização anatômica e disposição de tecidos têm interação direta com o volume foliar que sustenta (Pearcy \& Yang 1998). Assim, os pecíolos das folhas do tratamento sombra, que possuem maior volume, representados pelo maior comprimento, diâmetro e espessura dos tecidos de sustentação, estão relacionados aos maiores valores médios de área e massa da lâmina, observados neste tratamento. Como comentado anteriormente, houve um incremento em torno de 50\% na área e massa das folhas no tratamento sombra em relação ao tratamento pleno sol. Leeflang et al. (1998) consideram que o aumento de comprimento do pecíolo só ocorre com o incremento de biomassa deste, por meio de alterações dos tecidos mecânicos ou espessura, uma vez que este investimento é necessário para sustentação do peso da folha. Os mesmos autores ainda mencionaram que o crescimento do pecíolo é regulado por estímulos de luz que atingem a lâmina, o que mostra, segundo Niinemets \& Fleck (2002), a importância desta estrutura no posicionamento da folha para a captura de luz.

A análise dos componentes principais (PCA) mostrou que os dois primeiros componentes explicaram 75,6\% da variância total. PC1 explicou 62,5\% da variância e evidenciou a relação negativa entre a espessura total da lâmina com a área foliar, massa seca, teor de água e comprimento do pecíolo. O PC2, representado principalmente pela espessura total da lâmina, explicou $13,1 \%$ da variância e mostrou relação positiva com as demais variáveis (tabela 3). A figura 7 mostrou uma similaridade entre as folhas dos tratamentos meia-sombra e pleno sol, sugerindo uma preferência desta espécie por menores intensidades luminosas, pois níveis medianos de luz parecem exercer respostas semelhantes a condições de sol pleno.

A proximidade entre os valores médios das características morfológicas foliares das plantas dos tratamentos pleno sol emeia-sombra não era esperado, com base nos dados de intensidade luminosa dos tratamentos. Os valores próximos de intensidade luminosa entre os tratamentos sombra e meia-sombra $(13,8 \%$ e $26,4 \%$, respectivamente), embora as duas áreas apresentem uma composição e fitofisionomia diferenciada, sugeriam que as características morfológicas foliares quantitativas fossem similares entre estes dois tratamentos.

Aparentemente, as maiores incidências luminosas não restringem o crescimento e desenvolvimento da espécie, apesar dos menores valores de massa obtidos em condições de maior luz. Na Região Sul do Brasil, $M$. glomerata tem seu registro de ocorrência predominante em beira e interior de mata (Ritter \& Waechter 2004), indicando o caráter ciófito desta espécie.

Os ajustes das características morfológicas em função da variação de intensidade luminosa mostram a plasticidade da espécie em estudo, do ponto de vista ecológico. No entanto, para o produtor, o desempenho da espécie em cada tratamento é definido pela massa fresca e seca foliar produzida o que reflete na adoção de técnicas de manejo e ganhos de produtividade. A condição de maior sombreamento, com base nas características observadas, apresentou os maiores valores de massa fresca e seca, entretanto, estudos referentes às taxas de crescimento da planta, respostas sazonais e condições nutricionais diferenciadas podem complementar as informações para adoção de métodos de cultivo mais eficientes.

Agradecimentos - Os autores agradecem à Coordenação do Curso de Pós-Graduação em Botânica pelo apoio logístico, à Capes pela concessão de bolsa de mestrado ao primeiro autor, à Fundação Araucária pelo financiamento do projeto, ao Prof. Dr. Valmiqui Costa Lima pela identificação do solo e informações pedológicas sobre a região de realização do experimento e aos proprietários da fazenda Capão Bonito pela viabilização do experimento.

\section{Referências bibliográficas}

ACKERLY, D.D., DUDLEY, S.A., SULTAN, S.E., SCHMITT, J., COLEMAN, J.S., LINDER, C.R., SANDQUIST, D.R., GEBER, M.A., EVANS, A.S., DAWSON, T.E. \& LECHOWICZ, M.J. 2000. The evolution of plant ecophysiological traits: recent advances and future directions. BioScience 50:979-995. 
ALVES DE BRITO, C.J.F. \& ALQUINI, Y. 1996. A new method for staining botanical material embedded in glycol-methacrylate (GMA). Arquivos de Biologia e Tecnologia 39:949-951.

CAO, K.F. 2000. Leaf anatomy and chlorophyll content of 12 woody species in contrasting light conditions in a Bornean heath forest. Canadian Journal of Botany 78:1245-1253.

CASTRO, E.M., GAVILANES, M.L., ALVARENGA, A.A., CASTRO, D.M. \& GAVILANES, T.O.T. 1998. Aspectos da anatomia foliar de mudas de Guarea guidonea (L.) Slumer, sob diferentes níveis de sombreamento. Daphne 8:31-35.

CASTRO, E.M., PINTO, J.E.B.P., ALVARENGA, A.A., LIMA JÚNIOR, E.C., BERTOLUCCI, S.K.V., SILVA FILHO, J.L. \& VIEIRA, C.V. 2003. Crescimento e anatomia foliar de plantas jovens de Mikania glomerata Sprengel (guaco) submetidas a diferentes fotoperíodos. Ciência e Agrotecnologia 6:1293-1300.

CELEGHINI, R.M.S., VILEGAS, J.H.Y. \& LANÇAS, F.M. 2001. Extraction and quantitative HPLC analysis of coumarin in hydroalcoholic extracts of Mikania glomerata Spreng. ("guaco”) leaves. Journal of the Brazilian Chemical Society 12:706-709.

DICKISON, W.C. 2000. Integrative plant anatomy. Harcourt Academic Press, San Diego.

EMBRAPA. 1999. Sistema brasileiro de classificação de solos. Empresa Brasileira de Pesquisa Agropecuária, Centro Nacional de Pesquisa de Solos, Rio de Janeiro.

EVANS, J.R. 1999. Leaf anatomy enables more equal access to light and $\mathrm{CO}_{2}$ between chloroplasts. New Phytologist 143:93-104.

FAHN, A. 1990. Plant anatomy. Pergamon Press, Oxford.

GIVNISH, T.J. 1988. Adaptation to sun and shade: a wholeplant perspective. Australian Journal of Plant Physiology 15:63-92.

GIVNISH, T.J., MONTGOMERY, R.A. \& GOLDSTEIN, G. 2004. Adaptive radiation of photosynthetic physiology in the Hawaiian lobeliads: light regimes, static light responses, and whole-plant compensation points. American Journal of Botany 91:228-246.

GONÇALVES, J.F. DE C., MARENCO, R.A. \& VIEIRA, G. 2001. Concentration of photosynthetic pigments and chlorophyll fluorescence of mahogany and tonka bean under two light environments. Revista Brasileira de Fisiologia Vegetal 13:149-157.

HAMMER, O., HARPER, D.A.T. \& RYAN, P.D. 2001. PAST: Palaeontological statistics software package for education and data analysis. Palaeontologia Eletronica $4: 9$.

JOHANSEN, D.A. 1940. Plant microtechnique. Mc Graw Hill Book, New York.

KLICH, M.G. 2000. Leaf variations in Elaeagnus angustifolia related to environmental heterogeneity. Environmental and Experimental Botany 44:171-183.
LEEFLANG, L., DURING, H.K. \& WERGER, M.J.A. 1998. The role of petioles in light acquisition by Hydrocotyle vulgaris L. in vertical light gradient. Oecologia 117:235238.

LESSA-RICKLI, F., MACCARI, JR., A., MARIANO, J., FERNANDES, J.S.C. \& MAZUCHOWSKI, J.Z. 2003. Análise do desenvolvimento de plantas de erva-mate e de espécies nativas medicinais em três diferentes condições de luminosidade. In Anais do Terceiro Congresso Sul-Americano de Ervamate. (D.M. da Croce, coord.). Epagri, Chapecó, v.1, p.1-8.

MAACK, R. 2002. Geografia física do Estado do Paraná. Imprensa Oficial do Paraná, Curitiba.

MARQUES, A.R., GARCIA, Q.S. \& FERNANDES, G.W. 1999. Effects of sun and shade on leaf structure and sclerophylly of Sebastiana myrtilloides (Euphorbiaceae) from Serra do Cipó, Minas Gerais, Brazil. Boletim Botânico da Universidade São Paulo 18:21-27.

MILANEZE-GUTIERRE, M.A., MELLO, J.C.P. \& DELAPORTE, R.H. 2003. Efeito da intensidade luminosa sobre a morfo-anatomia foliar de Bouchea fluminensis (Vell.) Mold. (Verbenaceae) e sua importância no controle da qualidade da droga vegetal. Revista Brasileira de Farmacognosia 13: 23-33.

MONTANARI, R.M., SOUSA, L.A., LEITE, M.N., COELHO, A.D.F., VICCINI, L.F. \& STEFANINI, M.B. 2004. Plasticidade fenotípica da morfologia externa de Lippia alba (Mill.) N.E.Br. ex Britt. \& Wilson (Verbenaceae) em resposta a níveis de luminosidade e adubação. Revista Brasileira de Plantas Medicinais 6:96-101.

MORAIS, H., MEDRI, M.E., MARUR, C.J., CARAMORI, P.H., RIBEIRO, A.M.A. \& GOMES, J.C. 2004. Modifications on leaf anatomy of Coffea arabica caused by shade of Pigeonpea (Cajanus cajan). Brazilian Archives of Biology and Technology 47:863871.

NIINEMETS, U. \& FLECK, S. 2002. Petiole mechanics, leaf inclination, morphology, and investment in support in relation to light availability in the canopy of Liriodendron tulipifera. Oecologia 132:21-33.

PEARCY, R.W. \& YANG, W. 1998. The functional morphology of light capture and carbon gain in the Redwood forest understorey plant Adenocaulon bicolor Hook. Functional Ecology 12:543-552.

PIO-CORREA, M. 1984. Dicionário das plantas úteis do Brasil e das exóticas cultivadas. Imprensa Nacional, Rio de Janeiro, v.3, p.518.

POORTER, L. 1999. Growth responses of 15 rain-forest tree species to a light gradient: the relative importance of morphological and physiological traits. Functional Ecology 13:396-410. 
PORRA, R.J., THOMPSON, W.A. \& KRIEDMANN, P.E. 1989. Determination of accurate extinction coefficients and simultaneous equations for assaying chlorophylls a and b extracted with four different solvents: verification of the concentration of chlorophyll standards by atomic absorption spectroscopy. Biochimica et Biophysica Acta 975:384-394.

PRESS, M.C. 1999. The functional significance of leaf structure: a search for generalizations. New Phytologist 143:213-219.

RITTER, R.M. \& WAECHTER, J.L. 2004. Biogeografia do gênero Mikania Willd. (Asteraceae) no Rio Grande do Sul, Brasil. Acta Botanica Brasilica 18:643-652.

ROÇAS, G., BARROS, C.F. \& SCARANO, F.R. 1997. Leaf anatomy plasticity of Alchornea triplinervia (Euphorbiaceae) under distinct light regimes in a Brazilian montane Atlantic rain forest. Trees 11:469-473.

SANTIAGO, E.J.A., PINTO, J.E.B.P., CASTRO, E.M., LAMEIRA, O.A., CONCEIÇÃO, H.E.O. \& GAVILANES, M.L. 2001. Aspectos da anatomia foliar da pimenta longa (Piper hispidinervium C. DC.) sob diferentes condições de luminosidade. Ciências Agrotécnicas 25:1035-1042.

SILVA, L.M., ALQUINI, Y. \& CAVALLET, V.J. 2005. Interrelações entre anatomia vegetal e produção vegetal. Acta Botanica Brasilica 19:183-194.
SMITH, W.K., VOGELMANN, T.C., DELUCIA, E.H., BELL, D.T. \& SHEPHERD, K.A. 1997. Leaf form and photosynthesis: do leaf structure and orientation interact to regulate internal light and carbon dioxide? Bioscience 47:785-793.

TAIZ, L. \& ZEIGER, E. 2004. Fisiologia vegetal. Artmed, Porto Alegre.

VENDRAMINI, F., DÍAZ, S., GURVICH, D.E., WILSON, P.J., THOMPSON, K. \& HODGSON, J.G. 2002. Leaf traits as indicators of resource-use strategy in floras with succulent species. New Phytologist 154:147-157.

VOGELMANN, T.C., NISHIO, J.N. \& SMITH, W.K. 1996. Leaves and light capture: light propagation and gradients of carbon fixation within leaves. Trends in Plant Science 1:65-70.

WILSON, P.J., THOMPSON, K. \& HODGSON, J.G. 1999. Specific leaf area and leaf dry matter content as alternative predictors of plant strategies. New Phytology 143:155-162.

WITKOWSKI, E.T.F. \& LAMONT, B.B. 1991. Leaf specific mass confounds leaf density and thickness. Oecologia 88:486-493.

YANO, S. \& TERASHIMA, I. 2001. Separate localization of light signal perception for sun or shade type chloroplast and palisade tissue differentiation in Chenopodium album. Plant Cell Physiology 42:1303-1310. 